\title{
Morphological and micro-structural interface characterization in multilayer inverted polymer-fullerene bulk heterojunction solar cells
}

\author{
A. Jouane ${ }^{\mathrm{a}}$, R. Moubah ${ }^{\mathrm{a}}$, G. Schmerber ${ }^{\mathrm{b}}$, R. Lardéc ${ }^{\text {, Y. Odarchenko d,g }, \text { D. A. Ivanov }}{ }^{\mathrm{d}, \mathrm{f}}$, H. Lassri ${ }^{\mathrm{a}}$, Y. -A, Chapuis ${ }^{\mathrm{e}}$, \\ Y. Jouane $e^{\mathrm{b}, \mathrm{e}, *}$ \\ ${ }^{a}$ LPMMAT, Faculté des Sciences Ain Chock, University Hassan II of Casablanca, Morocco. \\ ${ }^{b}$ Université de Strasbourg, CNRS, IPCMS, UMR 7504, F-67000 Strasbourg, France. \\ ${ }^{c}$ Groupe de Physique des Matériaux, UMR 6634 CNRS, Université et INSA de Rouen, Avenue de l'Université, BP 12, 76801 Saint \\ Etienne du Rouvray Cedex, France \\ ${ }^{d}$ IS2M, Institut de Sciences des Matériaux de Mulhouse, UMR 7361 CNRS-UHA, 15 Rue Jean Starcky, BP 2488, 68057 Mulhouse Cedex, \\ France \\ ${ }^{e}$ Université de Strasbourg, CNRS, ICube, UMR 7357, F-67000 Strasbourg, France \\ ${ }^{f}$ Moscow Institute of Physics and Technology (State University), Institutskiy per. 9, Dolgoprudny, 141700, Russia \\ ${ }^{g}$ Department of Chemistry, University College London, 20 Gordon Street, London, WC1H OAJ, UK
}

\begin{abstract}
Inverted polymer solar cells based on P3HT/PCBM bulk heterojunction were prepared on flexible polyethylene naphthalate (PEN) substrate. The effect of annealing of the PEN/ITO/ZnO multilayer and ZnO/P3HT:PCBM on the structural, morphological, photophysical and photovoltaic properties was investigated and scrutinized directly on the OPV devices using atom probe tomography (APT), scanning electron microscopy (SEM) and microfocus X-rays techniques. We carried out a 3D reconstruction of the interfaces of the multilayer containing PEN/ITO, ZnO/ITO and P3HT:PCBM/ZnO to address the interface micro-structure and its influence on the morphology of the photoactive film. The analyses show that the morphology of the interfaces is affected by the structure of each layer of the BHJ devices causing orientation of P3HT crystals with PCBM aggregates and $\mathrm{ZnO}$, which in turn leads to a significant change of the charge transport across each layer and therefore photovoltaic performances.
\end{abstract}

Keywords: Atom Probe Tomography, Organic/Inorganic Heterostructures, Interface characterization, Flexible polymer-fullerene bulk heterojunction solar cells, Synchrotron micro-focus X-ray diffraction, Photoluminescence spectroscopy, Charge transfer.

\section{Introduction}

Flexible electronics holds a great promise for the development of future electronic devices. [1, 2] However, there are technological barriers which have still to be overcome for spreading their integration. The progress of power conversion efficiency (PCE) record is stimulated by the synthesis of new donor and acceptor materials, implementation of new interfacial materials and also the analysis and control of each interface in the bulk hetero-junction (BHJ) structure 3]. The interfaces between organic polymers, metals and interfacial layers are often problematic since an interface with a barrier height of a few tens of $\mathrm{mV}$ can result in significant charge build-up and therefore significant loss of recombination and photovoltaic performance. In addition, the inevitable potential loss due to the shift of the energy level at the interface between the donor and the acceptor renders the electrode contacts critical factor to derive the net potential out of the BHJs. Therefore,

\footnotetext{
* Corresponding author

Email address: yjouane@hotmail.fr (Y. Jouane)
}

the interface between the BHJ and both the anode and the cathode is of critical importance for charge transport and the extraction process, which determines device performance and long-term interfacial stability. Quantitative analysis of these interfaces is one of the keys to controlling the processing parameters, structure and performance of the final device. However, the interfacial analysis is challenging due to the complex chemistry of these interfaces. We note that nano-SIMS 4] is an interesting technique, which provides chemical details, whereas good-resolution imaging can be obtained in the energy-filtered transmission electron microscopy (EFTEM) [5.However, laserpulsed atom probe tomography (APT) combines sub-nanometer resolution with chemical sensitivity across the interface organic/inorganic. furthermore, APT is the only analysis technique offering extensive capabilities for both 3D imaging and chemical composition measurements at the atomic scale. Contrary to EDS which is limited for the light elements. APT can detect and quantify all elements (even hydrogen) present in the analysed material in the device structure with high sensi- 
tivity (about $50 \mathrm{ppm}$ ). However TEM or STEM analyses can provide complementary informations about crystal structure.

Considerable efforts have been devoted to the analysis and elucidation of the problems caused by interfaces since the evolution of polymer solar cells, but it is only recently that it begins to evoke the morphology and the modification of the structure of each layer of the BHJ devices, and its impact on photovoltaic efficiency. Other studies were focused on the vertical phase morphology and its transport process and charge collection in the case of the BHJ is sandwiched between the two electrodes [6]. Indeed, the effect of the interface property on the morphology of the photoactive film has gained immense attention, mainly in the methods on controlling the vertical composition gradient $\mathrm{D} / \mathrm{A}$ and the alignment of the energy at the $\mathrm{BHJ} /$ electrode/substrate interfaces. On the other hand, the use of flexible substrates is limited by the temperature window of annealing. Generally, two synthetic aromatic polyesters, polyethylene terephthalate (PET) and polyethylene naphthalate (PEN)] were previously used for flexible solar cells. 3] In addition, polyimides (PI) were often used as a polymer substrate, which has several advantages such as very high glass transition temperature (about $350^{\circ} \mathrm{C}$ ) and a competitive permeability compared to other substrates [6, 7]. Unfortunately, PI is not transparent, which is important for solar cells. Sderstrm et. al. [8] have textured the substrate by depositing a back reflector consisting of silver and zinc oxide in order to promote light scattering into the active layer. In addition, Ferekides et. al. 9] have developed flexible foil substrates for CdTe thin film solar cells based on flexible stainless steel (SS) substrate. However, in order to reach high device efficiencies on flexible substrates, further studies on the appropriate processes and materials used in the inverted organic solar cells are needed 9, 10. Here, we use poly(ethylene2,6-naphthalate) (PEN) as a substrate which cannot be heated above its glass transition temperature of $125^{\circ} \mathrm{C}$. However, its working temperature spans up to $155^{\circ} \mathrm{C}[1]$ and PEN has a very strong resistance to many diluted acids and solvents. On the other hand, permeability and thermal stability (melting temperature of $256^{\circ} \mathrm{C}$ ) of this aromatic polyester reduce the thermal distortion at the interface and must therefore maintain the integrity of the $\mathrm{ZnO}$ (cathode interfacial layer)/ITO(electrode) multilayer and the performance of photovoltaic devices. A detailed study on the impact of the quality of PEN flexible substrate on the morphology of the layers deposited beyond its thermal stability window as well as the interfaces in the layers stack of inverted organic solar cell is necessary.

In this paper we use atom probe tomography (APT), scanning electron microscope (SEM) and microfocus Xrays scattering techniques to analyze the interfaces directly in the OPV device and to obtain a $3 \mathrm{D}$ reconstruction of each of the interfaces in a multilayer containing PEN/ITO, ZnO/ITO and P3HT:PCBM/ZnO. In fact, the multilayer PEN-substrate /ITO/ZnO was annealed at a relatively low temperature limited by the polymer thermal stability. Its chemical and thermal stability as well as its crystalline structure was analyzed as a function of annealing temperature $\left(160\right.$ and $\left.180^{\circ} \mathrm{C}\right)$. To this end we study and explore the crystalline order in poly(3-hexylthiophene) (P3HT) that has a direct impact on the performance of the OPV device. The performance of the polymer supported solar cells is compared with the one on the rigid substrates (glass) which have been heat treated in the same way. Finally, additional photoluminescence (PL) analysis is used to explore the photophysical properties at the both interfaces ( $\mathrm{ZnO} / \mathrm{P} 3 \mathrm{HT}$ and $\mathrm{ZnO} / \mathrm{P} 3 \mathrm{HT}: \mathrm{PCBM})$ and the charge transport across active/electron selective layers. This study shows that the thermal activation and expansion through the PEN substrate caused structural and electronic modification of the interfaces in $\mathrm{PEN} / \mathrm{ITO} / \mathrm{ZnO}$ and $\mathrm{ZnO} / \mathrm{P} 3 \mathrm{HT}$ :PCBM multilayers and therefore the performance of organic photovoltaic devices.

\section{EXPERIMENTAL}

\subsection{Material and device elaboration}

The fabrication process of the organic solar cells (OSC) is detailed hereafter. PEN substrates $\left(20 \times 20 \mathrm{~mm}^{2}, \leq 15\right.$ $\Omega /$ sq.) (PECF-IP-Peccel Technologies, Inc.) were first cleaned in an ultrasonic bath with detergent acetone and isopropyl alcohol and deionized water (DI water). UV ozone cleaning was further performed for $30 \mathrm{~min}$. The $\mathrm{ZnO}$ target (from Neyco Co.) utilized for sputtering had a $99.999 \%$ purity. ZnO films were deposited on PEN/ITO substrates by RF magnetron sputtering under different deposition conditions such as working pressure, substrate temperature and deposition power 11, 12. The deposition was carried out in Ar atmosphere at a pressure of $10.10^{-3}$ mbar and a constant RF power of $100 \mathrm{~W}$. The substrate temperature was around $40^{\circ} \mathrm{C}$. The $\mathrm{ZnO}$ thickness was about $54 \mathrm{~nm}$. After $\mathrm{ZnO}$ deposition, one PEN/ITO/ZnO stack (as-prepared sample) was annealed in a quartz tube under a continuous oxygen flow for 1 hour, at different temperatures, between 160 to $180^{\circ} \mathrm{C}$. One as-prepared sample was not annealed and served as a reference. The rest of the stack (P3HT:PCBM/MoO $\mathrm{M}_{x} / \mathrm{Ag}$ ) was deposited in identical conditions for all samples. The photoactive layer was deposited on $\mathrm{ZnO}$ using spin-coating technique from a P3HT:PCBM poly(3-hexylthiophene) (P3HT) and [6,6]-phenyl C61 butyric acid methyl ester(PCBM) solution (1:1 weight ratio in dichlorobenzene) to form a 120 nm-thick layer. The P3HT (98.5\% regioregular from Sigma Aldrich $\mathrm{GmbH})$ and the PCBM $\left(\mathrm{PC}_{61} \mathrm{BM}\right.$ from Nano-C) were used as received without further purification. The PEN/ITO/ZnO/P3HT:PCBM stacks were then annealed at $140^{\circ} \mathrm{C}$ for 15 min under nitrogen atmosphere (in glove box). Finally, $\mathrm{MoO}_{x}(99.99 \%$ from Sigma-Aldrich $\mathrm{GmbH}$ ) and silver (Ag) were deposited sequentially through a shadow mask by thermal evaporation in vacuum at 2 . $10^{-6}$ Torr. The structure of the cells developed in this 
study is shown schematically in Fig. 1. The thickness of $\mathrm{MoO}_{x}$ and $\mathrm{Ag}$ are found to be around 5 and $120 \mathrm{~nm}$, respectively. Device active area was about $9 \mathrm{~mm}^{2}$. For comparison the OSC devices were also prepared using rigid substrate and following the same procedure, based ITOcoated glass substrates from Przisions Glass \& Optik GmbH, Germany (CEC20S, $\leq 20 \Omega$ /sq., $20 \times 20 \mathrm{~mm}^{2}$ ).

\subsection{Device characterization}

X-ray diffraction (XRD) was performed using a Rigaku SmartLab diffractometer (200 mA, $45 \mathrm{kV}$ ) equipped with a Ge (220)x2 monochromator and using $\mathrm{CuK} \alpha 1$ incident radiation $(\lambda=0.154056 \mathrm{~nm})$. Symmetric $\omega-2 \theta$ scans were done on the OSC devices

Synchrotron-based micro-focus X-ray diffraction (SR- $\mu$ XRD) measurements were carried out at the ID13 beamline of the ESRF. The monochromatic X-ray beam with the wavelength of $1.0 \AA$ was focused down to $1 \mu \mathrm{m}$ along both axes using crossed Fresnel optics. The X-ray patterns were recorded with a FreLon fast CCD camera with a pixel size of $50 \mu \mathrm{m}$. The norm of the scattering vector $\mathbf{s}(|\mathbf{s}|=2 \sin \theta / \lambda)$ was calibrated using the diffraction peaks of corundum. The regions of interest on the sample were selected with an on-axis optical microscope operated in reflection mode. More technical details concerning applications of micro-focus X-ray scattering to studies of the semicrystalline polymer structure has been done by Ivanov et al. 13] The free-standing OSC devices mounted on a glass capillary were scanned with the help of an x-y gantry in transmission geometry (Fig. S1 in Supplementary material) in order to analyze the micro-structure of each individual layer in the stack as a function of thickness. The diffraction patterns were collected using a step of $2 \mu \mathrm{m}$. The data reduction and analysis including background correction, visualization and radial as well as azimuthal integration of the 2D diffractograms were performed using home-built routines designed in Igor Pro software (Wavemetrics Ltd.).

Atom probe tomography (APT). APT specimens (sharp tips) were prepared by lift-out method and standard milling [14] using a dual beam ZEISS Nvision 40. In order to reduce $\mathrm{Ga}$ implantation and avoid damages in the region of interest, the multilayered P3HT:PCBM/ZnO/ ITO/PEN stack was capped with about $800 \mathrm{~nm}$ of $\mathrm{Pt}$ and a final polishing was performed at low acceleration voltage $(2 \mathrm{kV})$. The tips were analyzed by laser-assisted wide-angle tomographic atom probe (LAWATAP) from CAMECA at $80 \mathrm{~K}$ in an ultrahigh vacuum chamber at a pressure of $10^{-10}$ ) mbar. Specimens were then field evaporated using 350 fs laser pulses (wavelength: $\lambda=342 \mathrm{~nm}$ )

Current density-voltage $(\mathrm{J}-\mathrm{V})$ characteristics of the OSCs were measured with a HP Agilent source measurement unit, under darkness and light exposure. For the latter, a solar simulator under AM 1.5 G conditions (Oriel Xenon $150 \mathrm{~W}$ ) was used. The light intensity was calibrated with a standard silicon solar cell using a light intensity of $\left.100 \mathrm{~mW} \cdot \mathrm{cm}^{-2}\right)$. The device performances were measured under nitrogen atmosphere.

Differential scanning calorimetry (DSC). The measurements were performed using a Q1000 DSC from TA Instruments (New Castle, DE) with a heating rate of $5^{\circ} \mathrm{C} \cdot \mathrm{min}^{-1}$. Empty aluminium pans were used for the sample and reference. Initially, the calorimeter baseline was determined using a sapphire standard sample. The temperature of the calorimeter was calibrated from the observed melting points of ultra-pure materials as stearic acid, indium and tin.

Photoluminescence (PL) analysis. PL experiments presented herein were conducted at room temperature using a $532 \mathrm{~nm}$ laser $(10 \mathrm{~mW})$ modulated at a frequency of $15 \mathrm{kHz}$ as excitation source. The sample luminescence was collected by an optical fiber and analyzed by a CCD camera.

\section{RESULTS AND DISCUSSIONS}

\subsection{Morphological and micro-structure of the PEN/ITO, $\mathrm{ZnO} / \mathrm{ITO}$ and $\mathrm{ZnO} / \mathrm{P} 3 \mathrm{HT}: \mathrm{PCBM}$ interfaces}

In inverted organic solar cells, the interfacial contact between the substrate and the electrode (ITO) and that of the cathode buffer layer $(\mathrm{ZnO})$ plays important role in the electron transport. In this part, we focus on the interface morphology of PEN/ITO and ITO/ZnO. Under thermal annealing, PEN substrate affects the arrangement of ITO deposited above, and consequently on $\mathrm{ZnO}$ particles beside ITO by the diffusion effect as well as the interface of P3HT:PCBM/ZnO, that can result in the hole blocking and affect the device performance. Furthermore, it is essential to study the disposition of the $\mathrm{ZnO} / \mathrm{ITO}$ interface and adjacent PCBM:P3HT mixture layer directly in the cell. For this purpose a micro-sample with multiple layers (a part with P3HT:PCBM, ZnO and ITO layers) taken from the as-prepared cell were prepared by FIB/SEM for atom probe tomography, in order to have a three-dimensional reconstruction of $\mathrm{ZnO} / \mathrm{ITO}$ and $\mathrm{P} 3 \mathrm{HT}: \mathrm{PCBM} / \mathrm{ZnO}$ multilayer. Fig. 2a displays the tip shape specimen prepared from the studied heterostructure by focused ion beam milling. The $3 \mathrm{D}$ reconstruction of the analyzed volume is shown in Fig. 2 $\mathrm{b}$. The spatial distribution of single and molecular ions species are clearly observable. Position of the light elements ( $\mathrm{H}$ and $\mathrm{C}$ atoms) presented mainly in the organic layer of P3HT:PCBM cannot be determined accurately. Nevertheless, a dominant monoatomic ion of the atomic carbon $(\mathrm{C}+, \mathrm{C} 2+)[15]$ characteristic of the mixture of P3HT/PCBM, have been detected (Fig. S2 in Supplementary material). However, a moderate atomic mass ions are completely absent from the mass spectrum. Indeed, evaporation of large molecular ions can be problematic for 3D reconstructions of the vertical composition gradient PCBM aggregates and P3HT crystallite. From the phase separation in the P3HT:PCBM layer near $\mathrm{ZnO}$, as information about the structure and orientation of the 


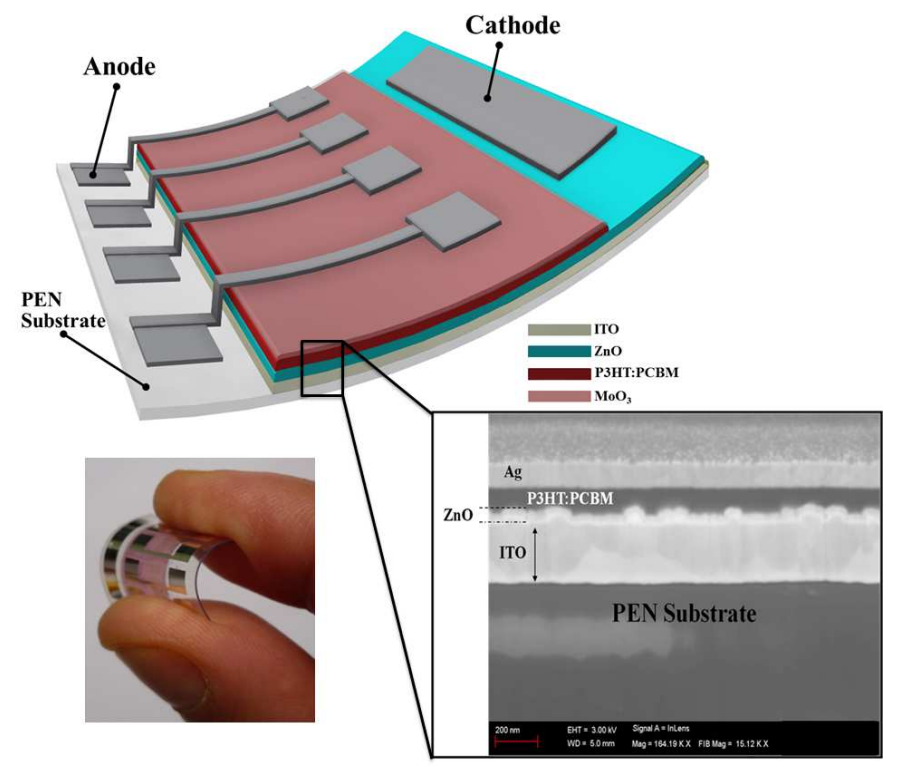

Figure 1: Schematic illustration of inverted organic solar cell (OSC) with cross-section scanning electron microscope (SEM) image for nonannealed stack (PEN/ITO/ZnO/P3HT:PCBM/MoO $/$ /Ag)

a)

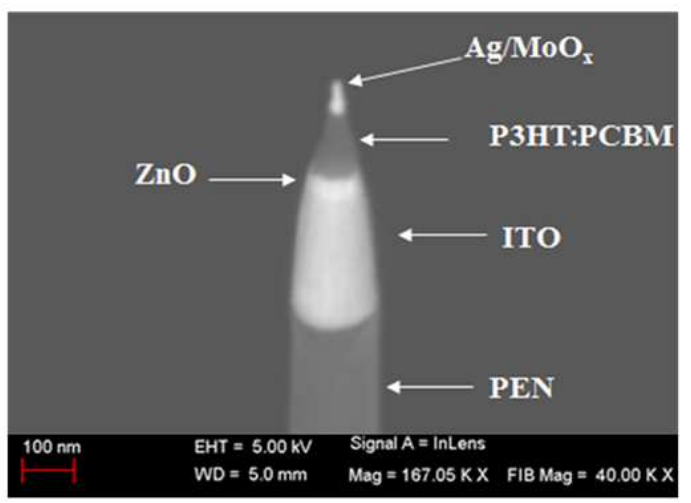

b)
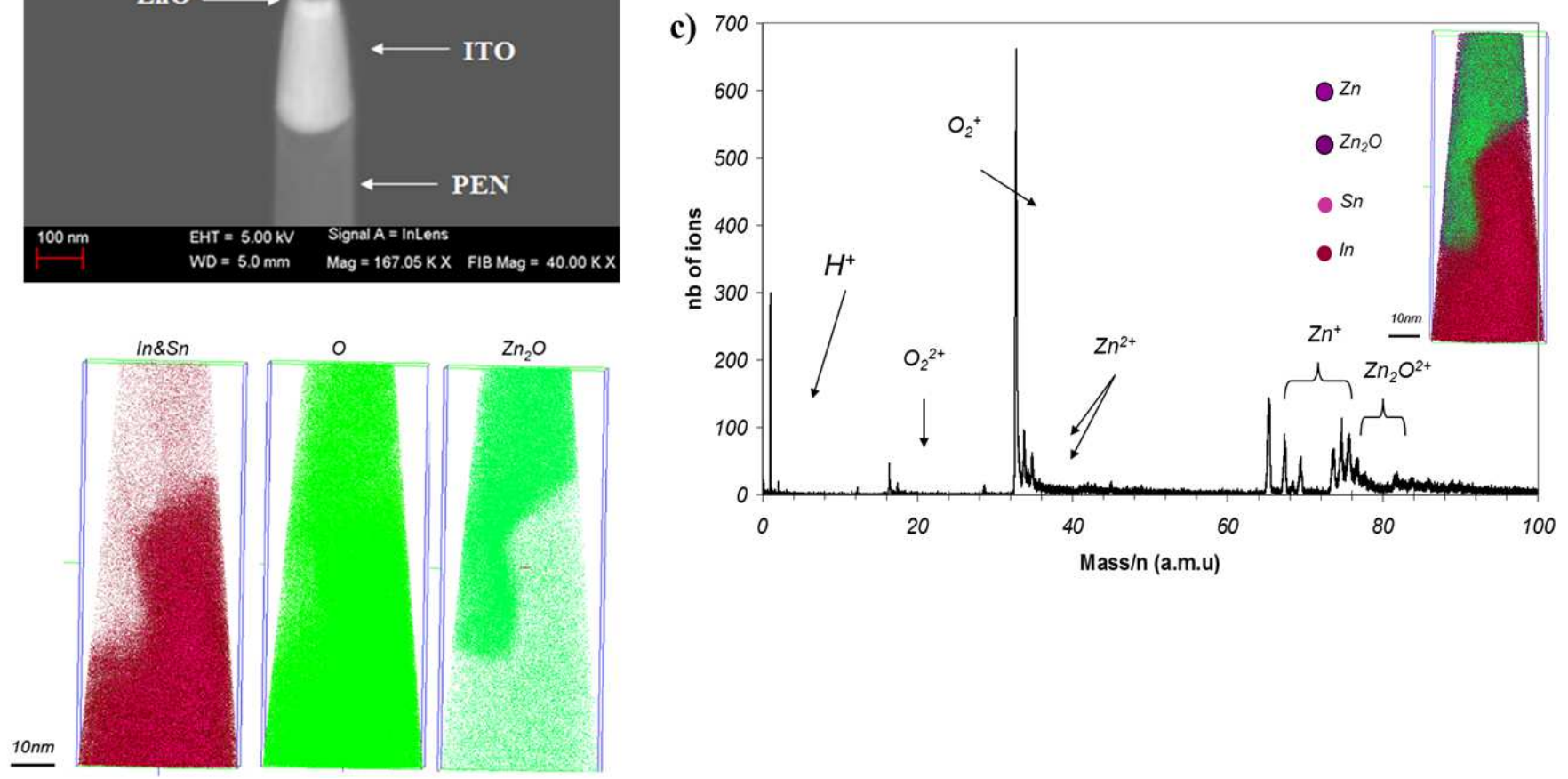

Figure 2: Atom probe tomography imaging of as-grown ZnO/ITO multilayer beside P3HT:PCBM layer. a) SEM micro-sample specimens of each layer in OSC structure. b) $\mathrm{ZnO}$ and ITO layers cartography. C) Mass spectrum micro-sample specimens focuses on ZnO and ITO films.

molecular ion is lost, effectively reducing the spatial resolution and thus not allow us to conclude about the chemistry spatial distribution near this interface. However, the spatial distribution of the other elements: In, Sn, Zn and O can be measured and studied (Fig. 20 and c). Our data in- dicate that inside layers the distribution of all these species is homogeneous. One can observe in Fig. 1 and Fig. 2b that the interface between ITO and $\mathrm{ZnO}$ layers is not sharp. In fact, a modulation of the chemical composition at the ITO/ZnO interface is observed due to a significant 

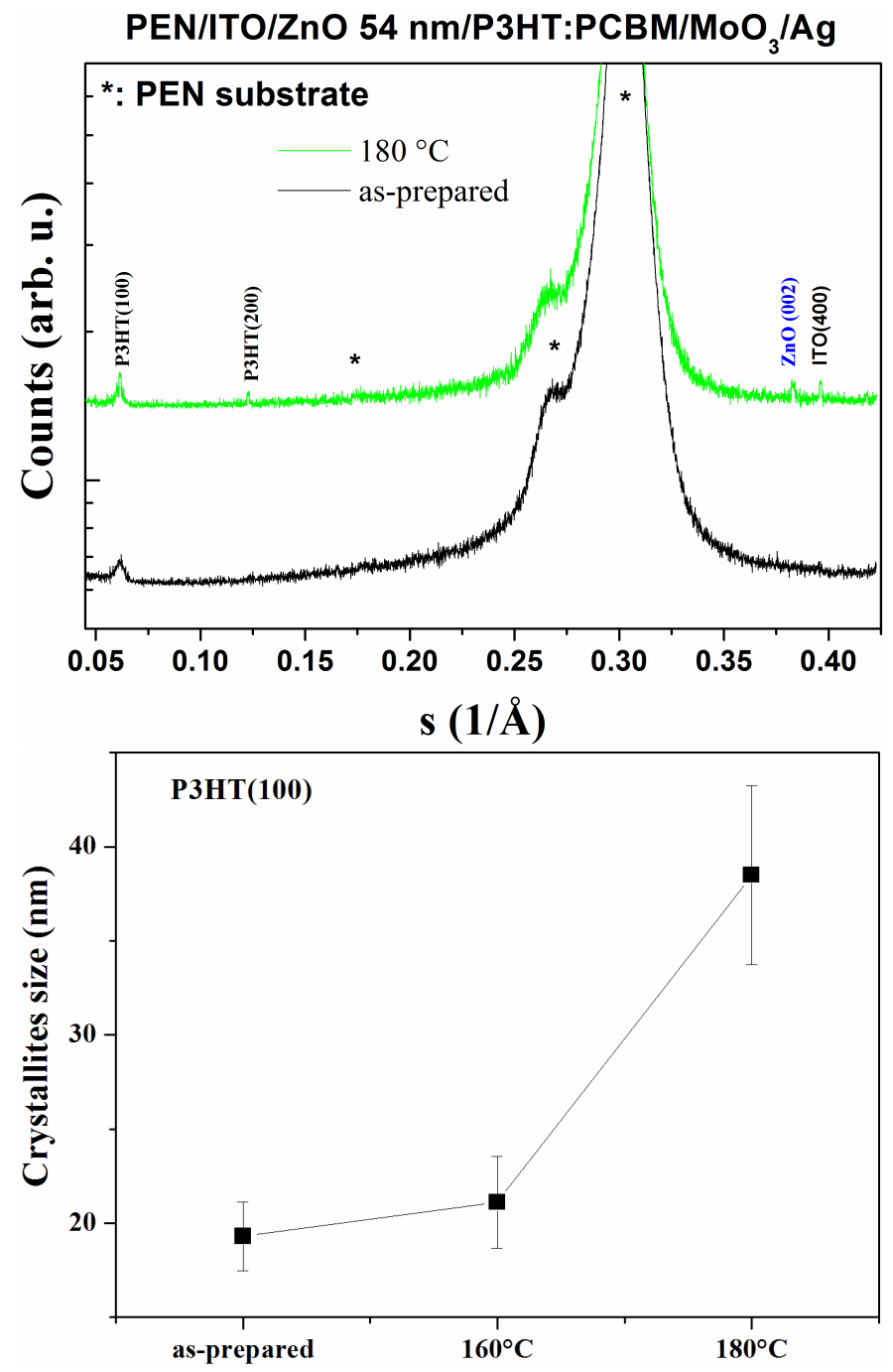

Figure 3: Effect of annealing on the OSC device studied by XRD a) XRD patterns of PEN/ITO/ZnO/P3HT:PCBM/ $\mathrm{MoO}_{x} / \mathrm{Ag}$ heterostructure for the as-grown and annealed at $180^{\circ} \mathrm{C} \mathrm{ZnO}$ layer. b) Change of the P3HT crystallites size as a function of $\mathrm{ZnO}$ annealing temperature for cells prepared on PEN substrate

rough interface which should strongly affect the interfacial roughness of the P3HT:PCBM organic layer, which is in agreement with the SEM observations in Fig. 1. These structural defects should mainly influence the interfacial molecular order of P3HT near $\mathrm{ZnO}$ layer and as a result the loss of electrons caused by charge recombination at defect sites 16. Such ordered profile promotes the vertical phase segregation and enhances the carrier mobility which should influence the charge transport and series resistance of photovoltaic cells and its performances [5, 16].

\subsection{Structural characteristics of PEN substrate, $\mathrm{ZnO}$ and P3HT}

$\mathrm{X}$-ray diffraction patterns recorded on $\mathrm{PEN} / \mathrm{ITO} / \mathrm{ZnO} /$ P3HT:PCBM $/ \mathrm{MoO}_{x}$ heterostructure for the as-grown and annealed at $180^{\circ} \mathrm{C}$ interfacial $\mathrm{ZnO}$ layer are displayed in Fig. 3a. The sample with $\mathrm{ZnO}$ annealed at $180^{\circ} \mathrm{C}$ ex- hibits different diffraction peaks which can be assigned to ITO, ZnO, and P3HT evidencing the well-defined crystalline structure of these layers. For the non-annealed samples, theses peaks are hardly visible showing that annealing improves the crystallinity of the main layers. The peak around the $\mathbf{s}$ of $0.38 \AA^{-1}$ in Fig. 3 a was identified as 002 reflection of the hexagonal wurzite form of $\mathrm{ZnO}$. For the as-prepared $\mathrm{ZnO}$, the 002 is very weak, which is indicative of a largely amorphous character of the non-annealed $\mathrm{ZnO}$ layer. Upon annealing at $180^{\circ} \mathrm{C}$, the 002 peak intensity significantly increases, and shows a preferred orientation of $\mathrm{ZnO}$ layer with the c-axis perpendicular to the PEN substrate. Contrary to other layers, the crystallinity of $\mathrm{ZnO}$ is greatly affected by annealing. The grain orientation in the c-axis direction is related to minimization of the free surface energy density of the film and its interface with the PEN/ITO substrate. The grain orientation in the c-axis direction is related to minimization of the free surface energy density of the film and its interface with the PEN/ITO substrate. Thus evolution of $\mathrm{ZnO}$ crystalline peaks will accompany that of ITO showing that the two phenomena of crystal growth are linked and continues. 17] Fig. 3b displays the change of P3HT crystallites size in the P3HT:PCBM layer calculated using DebyeScherrer formula from the 100 peak of P3HT observed at $\mathbf{s}$ of $0.062 \AA^{-1}$ (Fig. 3a). As can be observed, the crystallite size increases slowly with increasing annealing temperature at a first stage from as-grown to $160^{\circ} \mathrm{C}$, while the crystallite size increases more rapidly at higher annealing temperature $\left(180^{\circ} \mathrm{C}\right)$. The increase in annealing temperature of $\mathrm{ZnO} / \mathrm{ITO} / \mathrm{PEN}$ multilayer leads to an increase in motion of polymer molecules and chain mobility, which grown above. 18] Therefore, the P3HT forms larger crystals when deposited on highly crystalline $\mathrm{ZnO}$. The second diffraction peak of P3HT crystals observed at $0.124 \AA^{-1}$ and indexed as 200 appears after annealing at $180^{\circ} \mathrm{C}$, in addition to the (100) peak. These 001 peaks reveal straightened lamellar stacking with a slightly larger lattice spacing of $16.4 \AA$, which can be associated with the interdigitated alkyl chains 19, 20. The transformation and expansion of the PEN substrate ( $\mathrm{Tg}$ approaching $125^{\circ} \mathrm{C}$ for PEN substrate as shown in Fig. S3 in Supplementary material) facilitates the $\mathrm{ZnO}$ crystal growth and consequently, the enhanced orientation of P3HT lamellae along the edge-on of the surface normal direction. Note that the anisotropic texture and good P3HT and $\mathrm{ZnO}$ crystals orientation lead to a significant change in the characteristics of the photovoltaic devices. The most intense peaks around 0.25 $0.35 \AA^{-1}$ in Fig. 3 a were indexed as 100 and 110 peaks of the $\alpha$-crystal modification of PEN (i.e. the material of the substrate) 21. This peak is almost not influenced by annealing that indicates the structural stability of the flexible substrate used in this study. The 1D XRD analysis does not allow probing the possible anisotropy of the OPV device layers. Therefore $2 \mathrm{D}$ SR- $\mu \mathrm{XRD}$ scans of the OPV cross sections were carried out (cf. Fig. S1 in Supplementary material) for two samples: PEN/ITO substrate 
a)

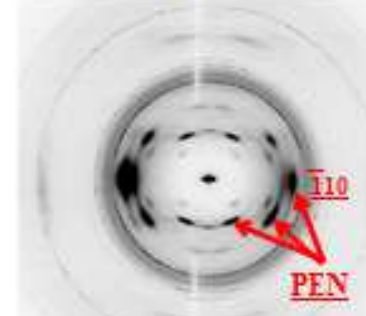

PEVTO

b)

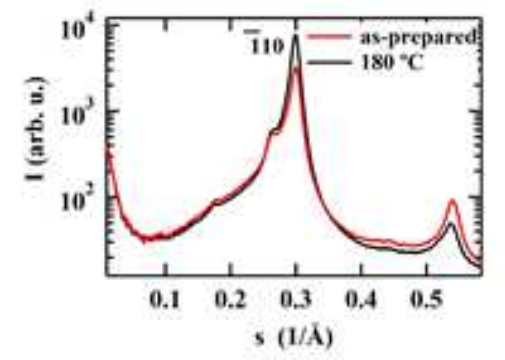

Figure 4: 2D $\mu \mathrm{XRD}$ images of P3HT/ZnO/ITO/PEN and PEN/ITO samples. The substrate orientation is vertical. b) Comparison of the 1D $\mu$ XRD equatorial profiles of PEN substrate corresponding to the same thickness ( $60 \mu \mathrm{m}$ from the surface) for the as-prepared and annealed at $180^{\circ} \mathrm{C} \mathrm{ZnO}$ layer

and P3HT:PCBM/ZnO/ITO/PEN structure annealed at $180^{\circ} \mathrm{C}$. Fig. 4 a compares the $2 \mathrm{D} \mu \mathrm{XRD}$ patterns taken at the surface of as-prepared ITO/PEN sample and the surface after P3HT deposition on $\mathrm{ZnO} / \mathrm{ITO} / \mathrm{PEN}$ multilayer stack that was annealed at $180^{\circ} \mathrm{C}$. One can see the typical fiber-like pattern 22, 23 indicating that the as-received flexible PEN substrate is highly oriented with its polymer backbone directed along the substrate surface and the normal to the substrate being along the 1-10 reciprocal-space vector of the PEN unit cell. The $1 \mathrm{D}$ XRD and 2D SR$\mu \mathrm{XRD}$ are in good agreement. The well-oriented 100 peak of P3HT with $\mathrm{d} \approx 16.4 \AA$ has equatorial orientation, which means that the P3HT chains are parallel to the PEN substrate and arranged with the molecular planes perpendicularly to the substrate. Fig. 40 compares the equatorial SR- $\mu \mathrm{XRD}$ profiles corresponding to the same thickness (i.e. at ca. $60 \mu \mathrm{m}$ distance from the surface) for PEN substrate as prepared and annealed at $180^{\circ} \mathrm{C}$. Note that the crystalline structure and degree of orientation of the PEN substrate is unchanged after annealing at $180^{\circ} \mathrm{C}$, a temperature above its $\mathrm{Tg}$. Therefore, one can conclude that the crystalline structure and texture of the poly(ethylene-2,6-naphthalate) substrate is not affected by the annealing at $180^{\circ} \mathrm{C}$.

\subsection{Electrical and Photophysical characterization of PEN and $\mathrm{ZnO} / \mathrm{P} 3 \mathrm{HT}$ :PCBM interface}

The performance of our photovoltaic devices, J-V curves under illumination conditions were carried out (Fig. 5). The corresponding photovoltaic performances are summarized in Table 1 Fig. 5 shows the results obtained for flexible device (PEN substrate) and rigid device (glass substrate). In case of non-annealed substrate of PEN/ITO/ZnO multilayer, we obtained S-shape in J-V curve for both substrates. Annealing PEN/ITO/ZnO multilayer at $180^{\circ} \mathrm{C}$ reduces the $\mathrm{S}$-shape in J-V characteristics for flexible substrate, reaching an open circuit voltage Voc around $0.59 \mathrm{~V}$ for both substrates. The S-shaped characteristics observed for as-prepared samples can be explained by the poor conductivity of $\mathrm{ZnO}$ as-prepared compared to annealed samples and also by the defect interface P3HT/ZnO, which can promote poor charge transport and high value of the series resistance (Rs) until $83 \Omega . \mathrm{cm}^{2}$ for as-prepared sample (see Table 1 and Table 2). Moreover, the phenomenon of "counter-diode" could be induced by the phase separation effects of P3HT and PCBM beside $\mathrm{ZnO}$. By annealing $\mathrm{ZnO}$, these effects can induce more appropriate phase separation between P3HT and PCBM, which facilitates exciton dissociation and charge transport to the cathode. The latter can explain the decrease of Rs for the annealed sample at $180{ }^{\circ} \mathrm{C}$ which has almost reached its soil value $\left(15 \Omega . \mathrm{cm}^{2}\right)$ and its higher fill factor (FF) about $48 \%$, compared to the as- Prepared. On the other hand, for both flexible and rigid substrate the efficiency values are higher for annealing at $180^{\circ} \mathrm{C}$ and almost similar $(1.5 \%)$ with open circuit voltage value of $0.54 \mathrm{~V}$, for device with as-prepared PEN/ITO/ZnO multilayer substrate. More interestingly, in case of flexible substrate, annealing at $180^{\circ} \mathrm{C}$ contributes mostly to improve the performance, therefore a perfect diode characteristic in its $\mathrm{J}-\mathrm{V}$ curve. This is accompanied by a sharp increase in fill factor (FF) up to $49 \%$ compared to the value of $33 \%$ obtained for as prepared PEN/ITO/ZnO multilayer substrate. The short-circuit current density (Jsc) is higher for PEN/ITO/ZnO multilayer annealed at $180^{\circ} \mathrm{C}(7.67$ $\mathrm{mA} / \mathrm{cm}$ ) and its efficiency attain up to $2.18 \%$. Indeed, the $\mathrm{J}-\mathrm{V}$ characteristic for the device made on PEN substrate with PEN/ITO/ZnO multilayer annealed at $180^{\circ} \mathrm{C}$ is not perfect with a ligther S-shaped behavior located towards the $\mathrm{x}$-axis (Voltage) compared to that on rigid substrate. To clarify this point, we have measured the conductivity of the ITO layer on PEN substrate before and after annealing $\left(160\right.$ and $\left.180^{\circ} \mathrm{C}\right)$ as shown in Table 2. It is found that the conductivity decreases for the PEN/ITO substrate annealed at $180^{\circ} \mathrm{C}$. This decrease can partly explain the decrease in photovoltaic performance for device compared to that at $160{ }^{\circ} \mathrm{C}$, knowing that the series resistance remained the same about $15 \Omega . \mathrm{cm}^{2}$.

In fact, according to Atom probe tomography in section A, thermal energy produced by annealing treatment was transferred to $\mathrm{ZnO}$ layer which favor reorganization of surface to find the most stable state and a more homogeneous structure, which contributes to the spread of the particles of ITO and $\mathrm{ZnO}$ giving rise to an increase of crystallites size $(20 \mathrm{~nm})$ as calculated from XRD data. In order to go further to explain this mechanism, the mea- 
Table 1: SUMMARY OF THE PHOTOVOLTAIC PARAMETERS OF INVERTED OPVS INTEGRATING ZnO CATHODE WITH NO ANNEALING AND ANNEALING AT DIFFERENT TEMPERATURES

\begin{tabular}{|c|c|c|c|c|c|c|c|}
\hline Substrate & Sample & Voc $(\mathbf{V})$ & $\left.\mathbf{J s c} \mathbf{( m A} / \mathbf{c m}^{2}\right)$ & $\mathbf{F F}(\mathbf{\%})$ & $\eta \mathbf{( \% )}$ & $\mathbf{R}_{s}\left(\boldsymbol{\Omega . c m}^{\mathbf{2}}\right)$ & $\mathbf{R}_{s h}\left(\boldsymbol{\Omega . c m}^{\mathbf{2}}\right)$ \\
\hline \hline \multirow{2}{*}{ glass } & As-prepared & 0.59 & 7.36 & 31.38 & 1.29 & 30 & 111 \\
& $180^{\circ} \mathrm{C}$ & 0.59 & 9.067 & 47.25 & 2.54 & 15 & 324 \\
\hline \hline \multirow{2}{*}{ PEN } & As-prepared & 0.54 & 5.53 & 32.85 & 1.5 & 83 & 328 \\
& $160^{\circ} \mathrm{C}$ & 0.57 & 9.17 & 49.18 & 2.58 & 15 & 449 \\
& $180^{\circ} \mathrm{C}$ & 0.58 & 7.67 & 48.75 & 2.18 & 15 & 512 \\
\hline
\end{tabular}

Table 2: SUMMARY OF THE HALL EFFECT MEASURMENTS OF PEN/ITO, NO ANNEALED AND ANNEALED AT DIFFERENT TEMPERATURES $\left(160\right.$ AND $\left.180^{\circ} \mathrm{C}\right)$

\begin{tabular}{|c|c|c|c|c|}
\hline Sample & Bulk concentration $\left(\mathbf{c m}^{-3}\right)$ & Resistivity $(\Omega . c m)$ & Mobility $\left(\mathbf{c m}^{2} /\right.$ V.s) & Roughness $(\mathbf{r m s})$ \\
\hline \hline PEN/ITO As-prepared & $1.39 \times 10^{21}$ & $1.27 \times 10^{-4}$ & 35.3 & - \\
\hline PEN/ ITO $160^{\circ} \mathrm{C}$ & $1.36 \times 10^{21}$ & $1.26 \times 10^{-4}$ & 35.4 & $3.8 \mathrm{~nm}$ \\
\hline PEN/ ITO $180^{\circ} \mathrm{C}$ & $1.28 \times 10^{21}$ & $1.56 \times 10^{-4}$ & 31.2 & $4 \mathrm{~nm}$ \\
\hline
\end{tabular}

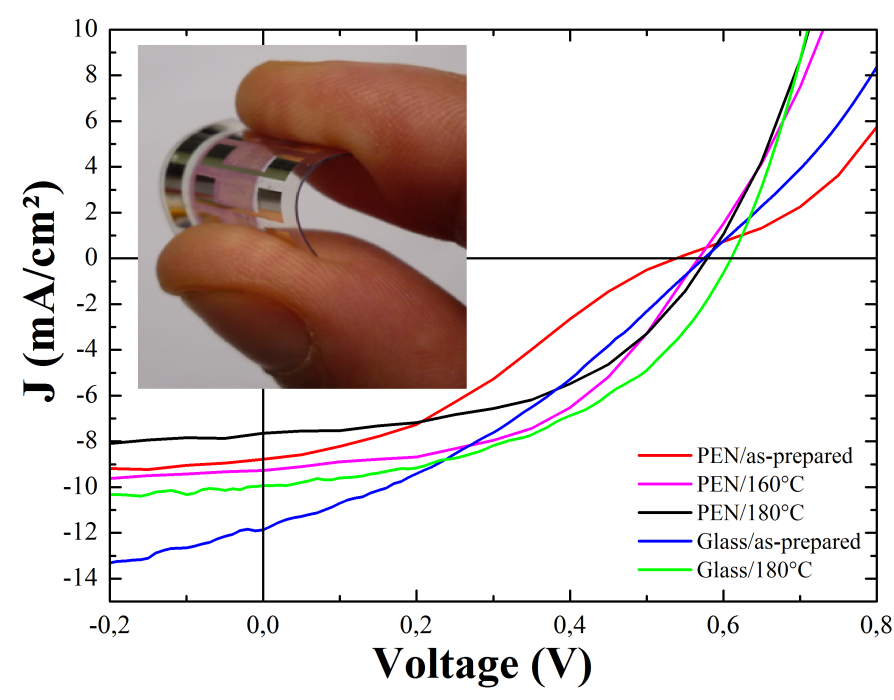

Figure 5: J-V characteristics of the both substrate (PEN/glass)/ITO/ZnO/P3HT:PCBM/ $\mathrm{MoO}_{x} / \mathrm{Ag}$ structure without and with annealing $\mathrm{ZnO}$ at 160 and $180^{\circ} \mathrm{C}$, under illumination

surements of differential scanning calorimetry (DSC) were carried out and allowed us to visualize the exothermic peak corresponding to the crosslink of PEN and also selecting the working temperature range of our substrate. We find that the glass transition temperature ( $\mathrm{Tg}$ ) was clearly detectable at about $130^{\circ} \mathrm{C}$ as shown in Fig. S3 in Supplementary material. Thus, the temperature above $130^{\circ} \mathrm{C}$ will change the crystalline state of PEN substrate as evidenced by Hardy et al. 24 who investigated mechanical relaxation behavior of dynamic for semi-crystalline oriented PEN films and observed an increase in the degree of crystallinity due to an increase in grain size. Indeed, once P3HT grows on $\mathrm{ZnO}$ layer, its growth is on large $\mathrm{ZnO}$ grains, which induces an increase in grain size of P3HT as shown previously in Fig. 3p. In addition, P3HT crystallite size increases sharply during annealing at $180^{\circ} \mathrm{C}$, since a value of $40 \mathrm{~nm}$ is obtained. Jouane et al. 19] have shown that this sharp increase will induce a significant decrease in the density at the interfaces of the active layer shown by the heterojunction donor/accepter based on P3HT: PCBM (that means the surface area to volume ratio), which will result in a reduction of the photocurrent generated by the device at $180^{\circ} \mathrm{C}$. Such a process could therefore explain the drop in short-circuit current density ( $\mathrm{Jsc}$ ) observed on flexible substrate annealed at $180{ }^{\circ} \mathrm{C}$ compared to that at $160{ }^{\circ} \mathrm{C}$. This should limit PCBM diffusion within $\mathrm{ZnO}$ layer, which can explained the decline in photovoltaic performance to $180^{\circ} \mathrm{C}$. Finally, we conclude that the thermal stability of PEN substrate can also contribute to change the surface quality which can affect the growth of upper layers (ITO and $\mathrm{ZnO}$ ) and thus the photoactive polymer. However, this stability naturally beneficial to the crystallization of $\mathrm{ZnO}$ and ITO (Fig. 3), and thus to the interfacial stability, ITO conductivity and $\mathrm{ZnO}$ surface roughness (Fig. 2). This latter can have an adverse consequence on contact beside active layer P3HT:PCBM/ZnO. In order, to clarify this point, the PL spectra of P3HT, P3HT/ZnO, P3HT:PCBM/ZnO (20, 54 and $100 \mathrm{~nm}$ ) and P3HT:PCBM were measured to assess the state of interactions between the different layers in the device at the excited state which can provide evidence of the exciton recombination within different interfaces. Note that the PL experiments were repeated and normalized with respect to the optical density. Fig. 6 displays the PL spectra for each case previously mentioned. The laser excitation is close to the maximum absorption peak of P3HT (550 nm), and far to the absorption peak of $\mathrm{ZnO}$. As can be observed, three emission peaks of P3HT centered at $648 \mathrm{~nm} 710$ and $780 \mathrm{~nm}$, which correspond to 
the vibronic structures of P3HT. The PL emission peak at about $648 \mathrm{~nm}(1.91 \mathrm{eV})$ is associated with pure electronic transition of P3HT and the peaks at $710 \mathrm{~nm}(1.74 \mathrm{eV})$ to the first vibronic band 25 27]. However, the PL emission at $780 \mathrm{~nm}(1.5 \mathrm{eV})$ shows an order in the lamellar structure of P3HT, which could promote vertical segregation of P3HT and PCBM molecules and as a consequence the electronic communication between the donor and acceptor layers. Therefore, the charge transfer and transport until $\mathrm{ZnO}$ cathode interfacial layer will be facilitated. In addition, the PL intensity for ZnO/P3HT:PCBM continuously increases with increasing $\mathrm{ZnO}$ thickness (20, 54 and $100 \mathrm{~nm})$. The exact mechanism of this behavior in exciton dissociation rate is uncertain and could be linked to defects induced by $\mathrm{ZnO}$ thickness increase. Note that the PL intensity was totally quenched in P3HT:PCBM thin films indicating a very effective charge transfer between P3HT and PCBM. Moreover, the PL intensity was not fully quenched in $\mathrm{ZnO} / \mathrm{P} 3 \mathrm{HT}$ double layers, but a slight decrease in luminescence compared to that observed for pure P3HT, which indicates a negligible charge transfer from $\mathrm{P} 3 \mathrm{HT}$ to $\mathrm{ZnO}$. Indeed, the difference in dissociation efficiency of excitons in the various interfaces can also be explained by the difference in lifetime of excitons obtained by $\mathrm{PL}$ lifetime, as was reported by Lin, et al.28] who showed that $\tau_{P 3 H T}$ as larger than $\tau_{Z n O / P 3 H T}$. This can be understood by a fast non-radiative process of photogenerated excitons at the $\mathrm{ZnO} / \mathrm{P} 3 \mathrm{HT}$ interface. Most of photogenerated excitons carriers will be separated at the P3HT and PCBM interface and only a tiny fraction of excitons will be separated at the $\mathrm{P} 3 \mathrm{HT} / \mathrm{ZnO}$ interface for this reasons we have a lower PL intensity observed in $\mathrm{ZnO} / \mathrm{P} 3 \mathrm{HT}$. Furthermore, the PL intensity quenching observed in the ( $\mathrm{ZnO} / \mathrm{P} 3 \mathrm{HT}$ :PCBM) for 20-nm-thick $\mathrm{ZnO}$ is a bit stronger than that observed for 54 and $100 \mathrm{~nm}$, which is a signature of a better efficiency of transfer of charge at the interface P3HT:PCBM/ZnO (20nm). In order to investigate the electronic structure at the $\mathrm{ZnO} / \mathrm{P} 3 \mathrm{HT}: \mathrm{PCBM}$ interface and the influence of $\mathrm{ZnO}$ annealing on its work function we consider that the HOMO and LUMO levels of P3HT and PCBM will not be influenced by $\mathrm{ZnO}$ annealing, but instead by the exchange at the P3HT:PCBM/ZnO interface. The change in optical gap (Eg) of $\mathrm{ZnO}$ by annealing can influence the charge transport at the interface P3HT:PCBM/ZnO, and as a result can disrupt the interfacial molecular order of P3HT at the interface with $\mathrm{ZnO}$. Indeed, we carried out optical transmission measurements to extract $\mathrm{Eg}$ of $\mathrm{ZnO}$ in a glass/ITO/ZnO stack. We found a small variation in $\mathrm{Eg}$ (around $3.25 \mathrm{eV}$ ) for samples: without and with annealing at $180^{\circ} \mathrm{C}$. These results show that the influence of $\mathrm{ZnO} \mathrm{Eg}$ is not significant and that thermal annealing of PEN substrate affect the morphology and the surface roughness of $\mathrm{ZnO}$ layer.

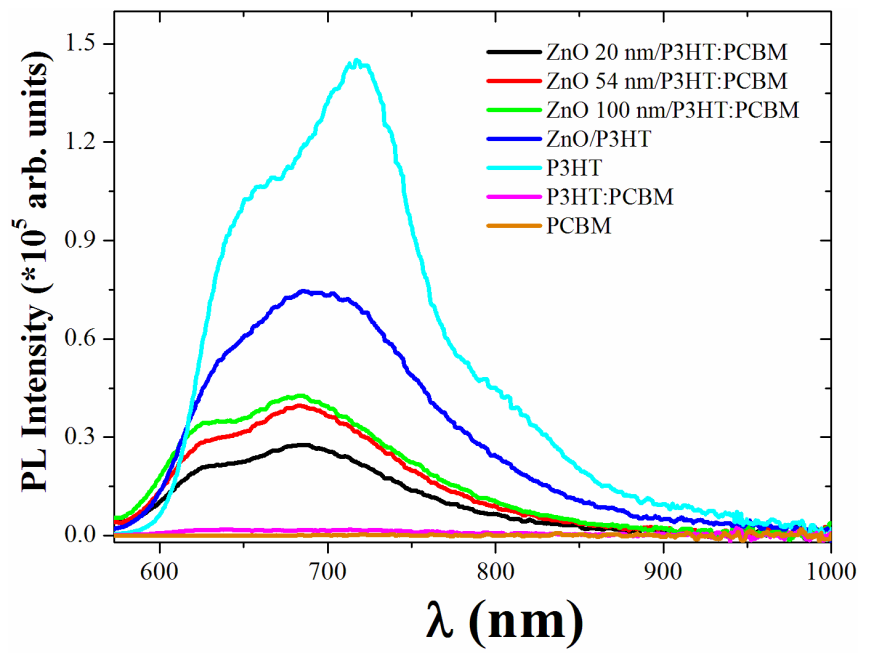

Figure 6: PL spectra of P3HT, P3HT:PCBM, P3HT/ZnO, P3HT:PCBM $/ \mathrm{ZnO}$ and PCBM films. b) Gaussian band fits of $\mathrm{P} 3 \mathrm{HT} / \mathrm{ZnO}$ by using an excitation wavelength of $532 \mathrm{~nm}$ in the range from 500 to $900 \mathrm{~nm}$

\section{CONCLUSION}

In summary, we have studied the interface morphology and the micro-structural modification of each layer of the BHJ devices, and their impact on photovoltaic efficiency. The growth of $\mathrm{ZnO}$ films on flexible substrates and application of thermal annealing at $140-180^{\circ} \mathrm{C}$ for flexible substrates (PEN/ITO) induce a change in the vertical composition gradient of the PCBM aggregates and P3HT crystallites in P3HT:PCBM film in the proximity of $\mathrm{ZnO}$. This change takes into account the thermal expansion of the flexible substrates and the induced energy, which contributes to the diffusion of the ITO and $\mathrm{ZnO}$ particles increasing the size of these crystallites. Indeed, this expansion is combined with a better organization of P3HT polymer chains which would favor the diffusion of PCBM at the interface with $\mathrm{ZnO}$. Consequently, the thermal activation of the charges up to $160{ }^{\circ} \mathrm{C}$ at the $\mathrm{ZnO} / \mathrm{P} 3 \mathrm{HT}: \mathrm{PCBM}$ interface led to a strong recovery of the performance of the cells, reaching values quite comparable to those obtained with rigid substrates. We finally succeeded to directly correlate the morphology of the interfaces with the microstructural and electronic modification of the interfaces of PEN/ITO/ZnO and ZnO/P3HT:PCBM multilayer and therefore with the performance of the flexible organic photovoltaic devices.

\section{ACKNOWLEDGMENTS}

This work was supported by the French Ministry of Research and Education. The authors are very grateful to T. Heiser, A. Dinia and S. Colis for fruitful discussions and N. Zimmermann, B. Heinrich and J. Bartringer for technical assistance. Y.O. and D.A.I. acknowledge the European project Interreg IV Rhin-Solar (no C25). D.I. thanks the Russian Ministry of Science and Education for financial 
support (contract N RFMEFI58716X0034). The authors are grateful to M. Burghammer from the ID13 beamline of the European Synchrotron Radiation Facility for the excellent technical support.

\section{References}

[1] P. Lper, B. Niesen, S. J. Moon, S. M. de Nicolas, J. Holovsky, Z. Remes, M. Ledinsky, F. J. Haug, J. H. Yum, S. D. Wolf, C. Ballif, Organicinorganic halide perovskites: Perspectives for silicon-based tandem solar cells, IEEE Journal of Photovoltaics 4 (6) (2014) 1545-1551. doi:10.1109/JPHOTOV.2014.2355421

[2] Y. Liu, N. Qi, T. Song, M. Jia, Z. Xia, Z. Yuan, W. Yuan, K.Q. Zhang, B. Sun, Highly flexible and lightweight organic solar cells on biocompatible silk fibroin, ACS Applied Materials \& Interfaces 6 (23) (2014) 20670-20675. doi:10.1021/am504163r

[3] K. Vandewal, K. Tvingstedt, A. Gadisa, O. Inganäs, J. V. Manca, Relating the open-circuit voltage to interface molecular properties of donor:acceptor bulk heterojunction solar cells, Phys. Rev. B 81 (2010) 125204. doi:10.1103/PhysRevB.81. 125204

[4] H. W. Ro, B. Akgun, B. T. O'Connor, M. Hammond, R. J. Kline, C. R. Snyder, S. K. Satija, A. L. Ayzner, M. F. Toney, C. L. Soles, D. M. DeLongchamp, Poly(3-hexylthiophene) and [6,6]-phenyl-c61-butyric acid methyl ester mixing in organic solar cells, Macromolecules 45 (2014) 6587-6599. doi:10.1021/ ma3008527

[5] R. C. Masters, A. J. Pearson, T. S. Glen, F.-C. Sasam, L. Li, M. Dapor, A. M. Donald, D. G. Lidzey, C. Rodenburg, Subnanometre resolution imaging of polymerfullerene photovoltaic blends using energy-filtered scanning electron microscopy, Nature Communication 6 (2015) 6928. doi:10.1038/ncomms7928

[6] R. Noriega, J. Rivnay, K. Vandewal, F. P. V. Koch, N. Stingelin, P. Smith, M. F. Toney, A. Salleo, A general relationship between disorder, aggregation and charge transport in conjugated polymers, Nature Materials 12 (2013) 1038-1044. doi:doi:10.1038/nmat3722

[7] C.-S. Ha, A. S. Mathews, Polyimides and High Performance Organic Polymers, Springer Berlin Heidelberg, Berlin, Heidelberg, 2011, pp. 1-36. doi:10.1007/978-3-642-19077-3_1

[8] K. Sderstrm, J. Escarr, O. Cubero, F.-J. Haug, S. Perregaux, C. Ballif, Uv-nano-imprint lithography technique for the replication of back reflectors for n-i-p thin film silicon solar cells, Progress in Photovoltaics: Research and Applications 19 (2) (2011) 202-210. doi:10.1002/pip.1003. URL http://dx.doi.org/10.1002/pip.1003

[9] V. Palekis, V. Guntur, D. Hodges, D. Morel, E. Stefanakos, C. Ferekides, Substrate based cdte solar cells fabricated on metallic foils: Device, material, and processing issues, in: Photovoltaic Specialists Conference (PVSC), 2011 37th IEEE, 2011, pp. 002779-002783. doi:10.1109/PVSC.2011.6186523

[10] W. A. MacDonald, J. M. Mace, Flexible Substrate Requirements for Organic Photovoltaics Wiley-VCH Verlag GmbH \& Co. KGaA, 2014, pp. 513-538. doi:10.1002/9783527656912. ch17 URL http://dx.doi.org/10.1002/9783527656912.ch17

[11] T. Higashioji, T. Tsunekawa, B. Bhushan, Mechanical property and dimensional stability of substrates for magnetic tapes, Tribology International 36 (46) (2003) 437 - 445, tribology of Information Storage Devices 2001. doi:http://dx.doi.org/10. 1016/S0301-679X (02)00232-3

[12] Y. Jouane, S. Colis, G. Schmerber, P. Kern, A. Dinia, T. Heiser, Y.-A. Chapuis, Room temperature zno growth by rf magnetron sputtering on top of photoactive p3ht:pcbm for organic solar cells, J. Mater. Chem. 21 (2011) 1953-1958. doi:10.1039/ COJM02354J

[13] M. Rosenthal, M. Burghammer, G. Bar, E. T. Samulski, D. A. Ivanov, Switching chirality of hybrid left right crystalline helicoids built of achiral polymer chains when right to left be- comes left to right, Macromolecules 47 (2014) 8295-8304. doi: 10.1021/ma501733n

[14] K. Thompson, D. Lawrence, D. Larson, J. Olson, T. Kelly, B. Gorman, In situ site-specific specimen preparation for atom probe tomography, Ultramicroscopy 107 (23) (2007) $131-139$. doi:http://dx.doi.org/10.1016/j.ultramic.2006.06.008

[15] T. PROSA, S. K. KEENEY, T. KELLY, Atom probe tomography analysis of poly(3-alkylthiophene)s, Journal of Microscopy 237 (2) (2010) 155-167. doi:10.1111/j.1365-2818. 2009.03320.x

URL http://dx.doi.org/10.1111/j.1365-2818.2009.03320.x

[16] Y. Jouane, S. Colis, G. Schmerber, C. Leuvrey, A. Dinia, P. Leveque, T. Heiser, Y.-A. Chapuis, Annealing treatment for restoring and controlling the interface morphology of organic photovoltaic cells with interfacial sputtered zno films on p3ht:pcbm active layers J. Mater. Chem. 22 (2012) 1606-1612. doi:10.1039/C1JM13569D

URL http://dx.doi.org/10.1039/C1JM13569D

[17] H.-C. Lee, O. O. Park, The evolution of the structural, electrical and optical properties in indium-tin-oxide thin film on glass substrate by $\{\mathrm{DC}\}$ reactive magnetron sputtering, Vacuum 80 (8) (2006) 880 - 887. doi:http://dx.doi.org/10.1016/j.vacuum. 2005.11.069

[18] C. B. Roth, J. R. Dutcher, Glass transition and chain mobility in thin polymer films, Journal of Electroanalytical Chemistry 584 (1) (2005) 13 - 22. doi:http://dx.doi.org/10.1016/j. jelechem.2004.03.003

[19] Y. Jouane, S. Colis, G. Schmerber, A. Dinia, P. Lvque, T. Heiser, Y.-A. Chapuis, Influence of flexible substrates on inverted organic solar cells using sputtered zno as cathode interfacial layer Organic Electronics 14 (2013) 1861 - 1868. doi:http://dx.doi.org/10.1016/j.orgel.2013.04.024 URL http://www.sciencedirect.com/science/article/pii/ S1566119913001833

[20] G. Li, V. Shrotriya, J. Huang, Y. Yao, T. Moriarty, K. Emery, Y. Yang, High-efficiency solution processable polymer photovoltaic cells by self-organization of polymer blends, Nature Materials 4 (2005) 864-868. doi:doi:10.1038/nmat1500

[21] C. van den Heuvel, E. Klop, Relations between spinning, molecular structure and end-use properties of polyethylene naphthalate tyre yarns, Polymer 41 (11) (2000) 4249-4266. doi:http: //dx.doi.org/10.1016/S0032-3861(99)00554-6

[22] J. R. May, C. Gentilini, D. E. Clarke, Y. I. Odarchenko, D. V. Anokhin, D. A. Ivanov, K. Feldman, P. Smith, M. M. Stevens, Tailoring of mechanical properties of derivatized natural polyamino acids through esterification and tensile deformation, RSC Adv. 4 (2014) 2096-2102. doi:10.1039/C3RA44865G.

[23] Y. I. Odarchenko, D. V. Anokhin, D. Doblas, M. Rosenthal, J. J. Hernandez, L. Vidal, N. J. Sijbrandi, A. J. Kimenai, E. P. C. Mes, R. Broos, G. Bar, P. J. Dijkstra, J. Feijen, M. Soloviev, D. A. Ivanov, Primary chemical sequence ultimately determines crystal thickness in segmented all aliphatic copolymers, Macromolecules 47 (22) (2014) 7890-7899. doi:10.1021/ma501545b.

[24] L. Hardy, I. Stevenson, A. Fritz, G. Boiteux, G. Seytre, A. Schnhals, Dielectric and dynamic mechanical relaxation behaviour of poly(ethylene 2,6-naphthalene dicarboxylate). ii. semicrystalline oriented films, Polymer 44 (15) (2003) $4311-4323$. doi:http://dx.doi.org/10.1016/S0032-3861(03)00332-X

[25] Y. Song, C. Hellmann, N. Stingelin, G. D. Scholes, The separation of vibrational coherence from ground- and excitedelectronic states in p3ht film, The Journal of Chemical Physics 142 (21). doi:http://dx.doi.org/10.1063/1.4916325

[26] S. Cook, A. Furube, R. Katoh, Analysis of the excited states of regioregular polythiophene p3ht, Energy Environ. Sci. 1 (2008) 294-299. doi:10.1039/B805643A

[27] J. A. McLeod, A. L. Pitman, E. Z. Kurmaev, L. D. Finkelstein, I. S. Zhidkov, A. Savva, A. Moewes, Linking the homo-lumo gap to torsional disorder in p3ht/pcbm blends, The Journal of Chemical Physics 143 (22). doi:http://dx.doi.org/10.1063/ 1.4936898

[28] Y.-Y. Lin, C.-W. Chen, T.-H. Chu, W.-F. Su, C.-C. Lin, 
C.-H. Ku, J.-J. Wu, C.-H. Chen, Nanostructured metal oxide/conjugated polymer hybrid solar cells by low temperature solution processes, J. Mater. Chem. 17 (2007) 4571-4576. doi:10.1039/B710400F 